\title{
O CENÁRIO DAS PESQUISAS INTERNACIONAIS SOBRE A INCLUSÃO E ESCOLARIZAÇÃO DO ALUNO COM DEFICIÊNCIA INTELECTUAL
}

\author{
Ana Paula Pacheco Moraes \\ Maturana \\ Universidade Federal de São Carlos/ \\ Faculdades Integradas de Jaú \\ Enicéia Gonçalves Mendes \\ Universidade Federal de São Carlos
}

\begin{abstract}
Resumo:
O presente trabalho tem como objetivo identificar e apresentar o que a literatura científica internacional recente traz sobre a escolha do tipo de escolarização para alunos com deficiência intelectual. Para tal, realizou-se uma pesquisa bibliográfica na base de dados Web of Sciencede pesquisas dos últimos 10 anos com os descritores: special education e inclusion. A leitura permitiu a identificação de dez produções relevantes para o tema, que foram apresentadas de acordo com seu respectivo país. De modo geral, os artigos abordaram a importância da participação dos pais na escolha do tipo de escolarização, o quanto a gravidade da deficiência influencia a percepção do tipo de escola adequada e a necessidade de medidas que façam com que os professores sintam-se atuantes e responsáveis pelo processo de inclusão do aluno com deficiência intelectual.
\end{abstract}

Palavras-chave: inclusão; deficiência intelectual; escolarização. 


\title{
THE SCENARIOOF INTERNATIONAL RESEARCHS ABOUT THE INCLUSION AND SCHOOLING OF STUDENTS WITH INTELLECTUAL DISABILITY
}

\begin{abstract}
:
This study aims to identify and present what the recent international scientific literature brings about the choice of schooling for students with intellectual disabilities. To this end, was performed a literature search in the database Web of Science of researches of the last 10 years with the descriptors: special education and inclusion. Reading allowed the identification of ten relevant productions to the subject, which were presented in accordance with their respective country. In general, the articles addressed the importance of parental involvement in choosing the type of schooling, how much the severity of the disability influences the perception of the appropriate type of school and the need for measures that make teachers feel they are active and responsible for the inclusion of students with intellectual disabilities process.
\end{abstract}

Key words: inclusion; intellectual disability; schooling. 


\section{Introdução}

Apesar do processo de inclusão dos alunos com deficiência estar previsto em lei, alguns entraves ainda são encontrados. Talvez, uma das categorias que apresente um dos maiores desafios para família, escola e o próprio aluno seja a escolarização de alunos com deficiência intelectual nas classes comuns das escolas regulares.

Enquanto as necessidades dos alunos com outras deficiências (como visual, física e auditiva) possam na maioria das vezes serem detectadas com maior facilidade, a fim de se oferecer instrumentos que viabilizem o aprendizado e o ensino, em relação ao aluno com deficiência intelectual as barreiras e dificuldades encontradas são de outra ordem. Não obstante todo o suporte conceitual e legal relacionado à caracterização da deficiência intelectual, para identificação e disponibilização de recursos e serviços adequados às necessidades destes alunos, verifica-se, ainda, a fragilidade desse processo. A identificação desse aluno, sua avaliação e estratégias educativas continuam sendo aspectos pouco claros para a grande maioria dos professores e profissionais que trabalham com esses alunos (VELTRONE, 2011).

Conforme afirma Padilha (2004) inserir o aluno com deficiência em escola regular não significa necessariamente que este aluno esteja “incluído". Portanto, a política inclusiva vai além da permanência física do aluno em sala comum, caminhando no sentido de revisão de paradigmas e concepções sobre a deficiência e o ensino desse aluno. Vale ressaltar o apontamento de Mendes (2010), que, analisando a quantidade de crianças e jovens públicoalvo da educação especial (cerca de 6 milhões de pessoas) e o número de matrículas dessa população nas escolas (aproximadamente $800 \mathrm{mil}$ ), atenta para o fato de que a grande maioria desses alunos está fora de qualquer tipo de escola.De acordo com Mendes (2010, p.106): 
As mazelas da educação especial brasileira, entretanto, não se limitam a falta de acesso, pois os poucos alunos com necessidades educacionais especiais que tem tido acesso a algum tipo de escola não estão necessariamente recebendo uma educação apropriada, seja por falta de profissionais qualificados ou mesmo pela falta generalizada de recursos.

Para Beyer (2010), a condição fundamental para a verdadeira inclusão escolar do aluno do Público Alvo da Educação Especial (PAEE) ${ }^{1}$, na escola comum é considerar que todas as crianças são únicas, em sua maneira de pensar e aprender. Logo, o ensino deve se organizar de maneira a contemplar todos os alunos, em suas diversas capacidades e potencialidades.

Ferramentas e suportes previstos em lei regulamentam a prática para a inserção do aluno com deficiência intelectual,em rede regular de ensino. Contudo, verifica-se que algumas propostas legais encontramse desconectadas com a realidade educacional de muitas escolas. Mendes (2006) afirma que tempos atrás a segregação era baseada na crença de que os alunos seriam melhor atendidos em suas necessidades educacionais, se ensinados em ambientes separados. Hoje, a ideia prevalecente é a de que eles podem e devem ser escolarizados nas classes comuns de escolas regulares, embora alguns pesquisadores defendam que o ensino dos estudantes comdeficiência intelectualdeva ocorrer em escola especial. Mas afinal, o que seria melhor para esses alunos; escola especial ou escola regular?

Nesse sentido, o presente artigo tem como objetivo identificar e apresentar o que a literatura científica internacional recente traz sobre a escolha do tipo de escolarização para alunos com deficiência intelectual.

\footnotetext{
${ }^{1}$ De acordo com o decreto $\mathrm{n}^{\circ} 7.611$ de 17 de novembro de 2011, a sigla PAEE significa público alvo da educação especial e engloba as pessoas com deficiência, com transtornos globais do desenvolvimento e com altas habilidades ou superdotação (BRASIL, 2011).
} 


\section{Método}

A pesquisa realizada pode ser caracterizada como exploratória (GIL, 1991). De acordo com o autor, esse tipo de pesquisa visa proporcionar maior familiaridade com determinado problema, a fim de torná-lo explícito ou construir hipóteses. A pesquisa exploratória pode utilizar, do ponto de vista de procedimentos técnicos, a pesquisa bibliográfica, com a finalidade de mapear e discutir a produção acadêmica e científica em determinada área de conhecimento, na tentativa de responder quais aspectos têm suscitado maior interesse dos pesquisadores, merecendo maior destaque e apontar possíveis lacunas.

Assim, quando se fala em pesquisa bibliográfica trata-se de um estudo exploratório sobre uma temática definida, que apresenta como principal vantagem permitir uma ampla cobertura de um dado fenômeno (GIL, 1991). Dessa forma, a fim de apontar um panorama internacional atual sobre a escolha do tipo de escolarização de alunos com deficiência intelectual foi realizada uma pesquisa bibliográfica na base de dados Web of Science, acessando diretamente a página do ISI Web of Knowledge e selecionando a aba Web of Science. As palavraschaves utilizadas foram: special education e inclusion. Optou-se por utilizar termos amplos, para que a procura abrangesse um grande número de produções, de modo que a seleção pelas pesquisas sobre o tema fosse realizada manualmente. Com o intuito de apresentar pesquisas recentes na área, foram considerados os trabalhos científicos produzidos no período 2004-2014.

\section{Resultados}


Em virtude da escolha dos descritores, foram encontrados 70 trabalhos científicos. Uma leitura pormenorizada permitiu a identificação de artigos que abordavam a temática investigada. Demais artigos que apareceram entre os 70 , mas não estavam relacionados ao tema em pesquisa, foram descartados.Dessa forma, foram selecionados para discussão da produção internacional dez artigos científicos relevantes para a temática abordada.Apesar de muitos desses artigos não estarem disponíveis para download gratuito, o contato com os autores por meio de correio eletrônico permitiu a obtenção de todo o material. Ressalta-se a disponibilidade dos autores, que prontamente responderam as mensagens eletrônicas e enviaram suas pesquisas.

Os trabalhos internacionais utilizam a sigla SEN (Special Educational Needs), para se referirem às crianças com necessidades educacionais especiais. Em cada país, a sigla SEN engloba uma população específica. $\mathrm{Na}$ Áustria, por exemplo, SEN engloba crianças com deficiências que possuem laudos médicos e crianças que não possuem laudos, mas que por outros motivos não alcancem os objetivos curriculares, como crianças com problemas de comportamento, por exemplo. Como a revisão englobou estudos referentes a crianças com deficiência intelectual, as diferenças conceituais sobre o que é a população com $\mathrm{NEE}^{2}$ dos países não influenciou os resultados. De modo geral, as pesquisas abordam a concepção de pais e professores de alunos com deficiência intelectual sobre a escolha do tipo de escolarização.

\section{Holanda / Países Baixos}

2 O termo Necessidades Educacionais Especiais (NEE) foi utilizado pela maioria das pesquisas internacionais e por isso será mantido na apresentação das mesmas. Em inglês, a sigla é representada por SEN (Special Educational Needs).

Olh@res, Guarulhos, v. 3, n. 1, p. 168-193. Maio, 2015. 
O artigo de Graaf, Hove e Haveman (2013) parte da situaçãoproblema de que pesquisas no Reino Unido demonstraram que crianças com Síndrome de Down adquirem mais habilidades acadêmicas quando escolarizadas no ensino regular. Lança-se então a questão: será que isso também é verdadeiro considerando a situação dos Países Baixos, mesmo após o efeito de colocação seletiva dos alunos em escolas regulares?

Tendo em vista a problemática, fez-se necessário ir além do artigo analisado e pesquisar documentos sobre a educação holandesa. De acordo com a legislação atual holandesa, sempre que possível as crianças com necessidades especiais têm a oportunidade de ser incluídas em escolas regulares, mas a decisão final é sempre deixada para os pais (SOUTHHOLLAND ANGLOINFO, 2014). Nos Países Baixos, em ambas as formas de educação, é obrigatório que as escolas, em consulta aos pais, façam um plano educacional individual.

Sendo assim, a hipótese do artigo de Graaf, Hove e Haveman (2013)é de que as diferenças nas habilidades acadêmicas entre alunos com Síndrome de Down de escola regular ou especialnão podem ser explicadas apenas pela colocação seletiva em um dos ambientes. Para tal, em 2006 foi enviado um extenso questionário para 160 pais de crianças com Síndrome de Down nascidasentre 1993 a 2000, que cursavam o ensino primário nos Países Baixos na escola especial e escola regular. A taxa de resposta dos pais foi de $76 \%$. O questionário continha perguntas relacionadas ao histórico escolar da criança, habilidades acadêmicas e não acadêmicas, quociente de inteligência, escolaridade dos pais, tempo em que os pais trabalham as habilidades acadêmicas com seu filho em casa, e a quantidade de tempo de instrução acadêmica na escola (GRAAF; HOVE; HAVEMAN, 2013).

Olh@res, Guarulhos, v. 3, n. 1, p. 168-193. Maio, 2015. 
Há de se considerar algumas variáveis que podem influenciar os dados da pesquisa, como por exemplo: as crianças com Síndrome de Down do ensino regular adquirem mais habilidades acadêmicas porque elas apresentam maior potencial e por isso estão na escola regular? Ou elas aprendem mais habilidades acadêmicas porque a educação regular é mais estimulante? De acordo com os autores do artigo, por motivos práticos e éticos, é impossível explorar essas questões por se tratar de uma pesquisaclínica randomizada (GRAAF; HOVE; HAVEMAN, 2013).

Os resultados apontaram que, a partir do estudo, parece que a quantidade de tempo dedicado ao ensino de habilidades acadêmicas desempenha um papel importante na aquisição de melhores habilidades acadêmicas. A colocação de crianças com Síndrome de Down em classes inclusivas é comparável ou até melhor que a de seus pares,em classes não inclusivas. Destaca-se que os dados obtidos sobre o desenvolvimento da criança passam pelo ponto de vista dos pais, isto é, os resultados podem ser interpretados como percepções subjetivas dos pais. Assim, o estudo demonstrou que crianças com Síndrome de Down em escolas regulares, de acordo com os pais, aprendem mais habilidades acadêmicas.

Contudo, essa não é uma consequência direta da colocação em ambiente inclusivo, mas também é determinada por outros fatores, tais como o funcionamento cognitivo, habilidades não acadêmicas, nível de escolaridade dos pais e o tempo em que os pais estudam com a criança em casa (GRAAF; HOVE; HAVEMAN, 2013).

O estudo de Boer, et al (2012) teveos objetivos: (1) examinar quais as variáveis que se relacionam com as atitudes de professores, pais e colegas em relação a alunos com transtorno de déficit de atenção e hiperatividade, transtorno do espectro autista (TEA) ou deficiência intelectual no ensino básico e (2) analisar se as atitudes de professores e pais afetam as atitudes dos colegas dessas crianças. A elaboração da 
pesquisa partiu da ideia de que a inclusão escolar de alunos com NEE em escolas regulares tornou-se uma questão importante nas políticas educacionais de muitos países. Entretanto, algumas pesquisas demonstram uma dificuldade de participação social do aluno com NEE na escola regular, lembrando que a inclusão em si não garante uma completa participação desse aluno nesse meio. Outros fatores a serem considerados, como dificuldade de relacionamentos sociais e aceitação dos pares, são levantados pela literatura internacional. Os autores Boer, et al (2012) apontam que as atitudes de pais, professores e pares diferem, em relação àseveridade da deficiência. Os dados demonstram que há uma tendência a uma percepção menos positiva sobre a inclusão escolar,quando se trata de alunos com deficiências cognitivas e problemas comportamentais,em níveis moderado a grave.

Sendo assim, Boer, et al (2012) realizaram um levantamento para avaliar as atitudes e os dados foram estudados, por meio de análises de vários níveis. Participaram 26 escolas primárias regulares da Holanda e um total de 49 salas de aula. A amostra contou com 44 professores, 508 pais e 1.113 colegas de sala, que responderam a um questionário com duas questões (BOER, et al, 2012). Em relação aos resultados, nenhuma das variáveis exploradas (sexo, anos de experiência de ensino, a assistência em sala de aula e experiência com educação inclusiva) estavam relacionadas com as atitudes dos professores. Para as atitudes de pais e pares, as variáveis sexo, a idade dos pares, ter uma criança com NEE e ser amigo de um aluno com NEE estavam relacionadas com as suas atitudes.

Quanto ao segundo objetivo, os autores concluíram que as atitudes dos professores têm um efeito negativo sobre as atitudes dos colegas, enquanto as atitudes dos pais têmum efeito positivo. Destarte, os autores apontam que mudar as atitudes dos pais e colegas pode ser um ponto de partida para a criação de mais aceitação, levando a mais benefícios sociais para esses alunos em escolas regulares (BOER, et al, 2012). Entretanto, os autores não deixam claro qual conceito de Olh@res, Guarulhos, v. 3, n. 1, p. 168-193. Maio, 2015. 
atitude utilizam, não operacionalizam o termo, assim como não apresentam de qual forma seria possível modificar essas atitudes.

\section{Áustria}

O estudode Gasteiger-Klicpera, et al (2013)abordou as atitudes e experiências de pais de crianças com déficit cognitivo, em relação à escolarização em escola especial e escola "inclusiva" (termo utilizado no artigo para se referir a escolas regulares com inclusão de alunos com necessidades especiais). De acordo com os autores, "nos últimos 20 anos, muitos países com uma educação especial bem desenvolvida substituíram o modelo de educação tradicional por classes especiais e escolas inclusivas" (GASTEIGER-KLICPERA, et al, 2013, p.663, tradução nossa). A taxa de integração de crianças com "necessidades educacionais especiais" (termo utilizado no artigo) na educação mainstreaming ${ }^{3}$, isto é, na escola regular, varia consideravelmente nos países europeus. Gasteiger-Klicpera, et al (2013) afirmam que, em 2010, na Alemanha essa taxa era de $16,8 \%$ e de $85,2 \%$ na Noruega, por exemplo.

De acordo com os autores, vários estudos empíricos sobre a implementação da educação especial em ambientes inclusivos apontam a relevância de atitudes integrativas de seus principais atores, como pais e professores. Cabe ressaltar que, na Áustria e nos países de língua alemã, os pais desempenham um papel essencial na escolha do tipo de escolarização dos filhos. Desde 1993, a escolha entre uma educação inclusiva na escola regular, ou uma educação em uma escola especial, depende principalmente da decisão dos pais. Dessa forma, a proporção de crianças austríacas com NEE educadas em classes inclusivas aumentou 50\%. A educação inclusiva na Áustria é

\footnotetext{
${ }^{3}$ De acordo com Mendes (2006), o termo mainstreaming pode ser traduzido como fluxo, corrente ou tendência principal e foi no Brasil traduzido como integração. Compreende-se que a educação mainstreaming é aquela realizada em escola regular.

Olh@res, Guarulhos, v. 3, n. 1, p. 168-193. Maio, 2015.
} 
caracterizada por aulas conjuntas com um educador especial e um professor da sala regular (GASTEIGER-KLICPERA, et al, 2013). Os autores apontam que várias formas de organização do trabalho dos dois professores são possíveis, mas que a cooperação entre eles durante o ensino é um desafio a ser enfrentado.

Assim, o objetivo do estudo foi conhecer as atitudes dos pais perante a escolarização dos filhos, em escolas regulares inclusivas ou em escolas especiais. Foi realizada uma survey com 840 pais através da aplicação de um questionário. Em relação ao progresso na escola, a grande maioria dos pais reportou experiências positivas. Os resultados apontaram que a maioria dos pais avalia os esforços feitos pelas escolas especiais de maneira positiva. Para os pais "a educação inclusiva é preferível para crianças com 'deficiência' de aprendizagem, enquanto crianças com deficiências severas e múltiplas podem se beneficiar com qualquer um dos dois tipos de escolarização" (GASTEIGER-KLICPERA, et al, 2013, p.677, tradução nossa).

Os dados apontaram também a insatisfação dos pais, em relação à comunicação com os profissionais que atuam com seus filhos. Para os pais de crianças com deficiências múltiplas e severas, os professores da escola inclusiva prestam menos atenção em seus filhos, e eles relatam que têm mais apoio de professores especiais. Ressalta-se que a satisfação dos pais com a escolarização dos filhos, de modo geral, foi positiva, mas encontrou-se diferenças marcantes, em relação à avaliação dos pais, dependendo do grau da deficiência e do tipo de escola (GASTEIGER-KLICPERA, et al, 2013).

\section{Alemanha}

O trabalho alemão "Kinder mit Lernstörungen und Behinderungen in integrativen Schulen oder in Sonderschulen? Die Sichtweise von Olh@res, Guarulhos, v. 3, n. 1, p. 168-193. Maio, 2015. 
Eltern und Fachleuten" (Crianças com dificuldades de aprendizagem e deficiências em escolas inclusivas ou em escolas especiais? O ponto de vista de pais e profissionais)foi realizado por uma equipe médica e escrito por Bode e Hirner (2013). De acordo com os autores, o trabalho investigou a visão de pais e profissionais sobre matricular crianças com necessidades educacionais especiais em escolas inclusivas (BODE; HIRNER, 2013).

Na Alemanha, a cooperação entre as Sonderschulen(escolas especiais) e escolas do mainstream (regulares)existe, independentemente de outras circunstâncias. Quando um aluno é transferido de um tipo de escola para outra, os professores e diretores das escolas trabalham em conjunto. É sempre possível para os alunos retornar às escolas regulares (EUROPEAN AGENCY, 2014). Em relação a essa transferência, a autoridade de educação toma a decisão sobre a possibilidade de transferir um aluno, mediante um pedido da escola especial ou dos pais ou responsáveis legais. Os alunos das escolas especiais podem ser admitidos na Grundschule (escola primária) ou na Hauptschule (escola de ensino médio), se houver chance deles realizarem as lições e alcançarem sucesso.

Na pesquisa de Bode e Hirner (2013), a amostra contou com 54 pais de crianças pré-escolares (faltando um ano para ingressar na escola) e 155 pais de crianças em idade escolar. Todas elas frequentavam um Centro Pediátrico Social. Como instrumento metodológico foram utilizados questionários para os pais e cuidadores de crianças préescolares e escolares. As questões abordaram as expectativas dos pais, as experiências referentes à escola e a severidade da deficiência da criança (BODE; HIRNER, 2013).

Como resultado, 135 crianças estudavam em escolas especiais e 20 em escolas integrativas. A correção dos questionários demonstrou que os pais, em sua maioria, estavam satisfeitos com os dois tipos de escolas, apesar de $33 \%$ dos pais relatarem não ter tidouma livre escolha da 
escola. Eles tinham uma atitude positiva para com a educação inclusiva. Alguns pais de crianças com NEE gostariam de enviar a sua criança para uma escola especial, outros preferiam escolas inclusivas. Cabe ressaltar que os autores apontam que o aconselhamento e a orientação aos pais sobre as escolhas do tipo de escolarização vêm aumentando na Alemanha.

\section{Reino Unido}

Buckley, et al (2006) tiveram por objetivo comparar as conquistas de adolescentes com Síndrome de Down educados em salas de aula regulares ou em salas de aula de educação especial. Os autores avaliaram o progresso dos alunos nas áreas de linguagem, alfabetização, socialização, habilidades da vida diária e comportamento. Os autores comparam dados de dois estudos, um em 1987 e outro em 1999. Em 1987 participaram 90 adolescentes com Síndrome de Down e em 1999, 46 adolescentes, sendo que 28 estudavam em escolas especiais e 18 em escolas inclusivas (regulares). Em ambos os estudos, os pais respondiam questionários padronizados enviados pelos pesquisadores.

Para todos os adolescentes, há evidência de progresso com a idade em todas as medidas, com exceção para a comunicação. A comunicação continuou a melhorar através dos anos da adolescência para as crianças incluídas, mas não para aqueles em salas de aula de educação especial. Não houve diferenças significativas nos resultados globais de habilidades da vida diária ou socialização. No entanto, houve grandes ganhos significativos de linguagem e alfabetização, para aqueles educados em salas de aula regulares. 
Os resultados também apontam que os adolescentes educados em salas de aula regulares apresentaram menos dificuldades comportamentais. De acordo com Buckley et al (2006), as implicações decorrentes do estudo para os pais e para os professores são de que todas as crianças com Síndrome de Down devem ser educadas emsalas de aula comuns, pois assim serão estimuladas a desenvolver a fala e a linguagem e poderão aprender junto com seus pares não deficientes e acessar o currículo escolar adaptado e individualizado.

\section{Irlanda}

Um estudo importante foi o artigo de Kelly, et al (2014), que trata da realidade irlandesa, na qual muitos alunos com NEE estão deixando o ensino regular (mainstream) e se matriculando em escolas especiais. Assim, o estudoteve como objetivo investigar as razões pelas quais os estudantes com 12 anos ou mais estão deixando o ensino regular e solicitando transferência para escolas especiais.

Kelly, et al (2014) explicam que a ideologia da educação inclusiva foi trazida para a Irlanda, por meio de ações governamentais, em conjunto com a Declaração de Salamanca de 1994. No país, até os anos 2004/2005 os alunos com NEE tinham uma opção de se inscrever em escolas especiais, desde que cumpridos os critérios relativos à categoria de deficiência, ou se inscrever em uma escola regular (em uma classe comum, classe especial ou em uma unidade educacional extraordinária).

Os dados da pesquisa de Kelly, et. al (2014) foram obtidos a partir de questionários enviados a 54 diretores de escolas especiais, que relataram suas experiências com 246 estudantes transferidos. Foi realizada uma análise estatística descritiva. De acordo com os dados analisados, a principal razão da transferência foi o fracasso das escolas 
regulares para satisfazer as necessidades acadêmicas, emocionais e comportamentais dos alunos.

Os problemas de ajustamento e integração resultaram da falta de um plano de transição entre as duas formas de escolarização, assim como a entrada tardia no currículo da escola especial e um excesso de dependência de apoio. Os diretores também reportaram que os alunos que voltavam para o ensino especial exibiam falta de autoconfiança, de engajamento na sala de aula, dificuldade na interação entre pares e comportamento desafiador. Os diretores atribuíram essas disfunções ao descompasso entre as necessidades educacionaisespeciais e a outros aspectos dos alunos e aos ambientes educacionais (KELLY, ET. AL.,2014). Os autores concluem que os desafios atuais enfrentados pelas escolas especiais na Irlanda não são um fenômeno exclusivo daquele país, pois várias nações ainda lutam para introduzir práticas inclusivas, em meio a restrições de recursos socioeconômicos e educacionais (KELLY, ET. AL.,2014).

\section{Espanha}

Em relação à Espanha, o estudo"Inclusive Education in Spain: how do skills, resources, and supports affect regular education teachers' perceptions of inclusion?" de Chiner e Cardona (2013) investigou a percepção de professores do ensino regular de escolas primárias e secundárias sobre a inclusãoescolar e como essas percepções podem diferir, dependendo da experiência de ensino, habilidades e da disponibilidade de recursos e suporte.

De acordo com Chiner e Cardona (2013), tanto na educação infantil, como no ensino fundamental e médio, alunos com NEE estão incluídos em salas de aula regulares. Atualmente, o ensino médio completo e nível universitário trabalham com práticas inclusivas.

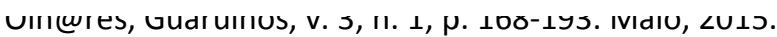


Dessa maneira, a Espanha é considerada um dos sistemas educacionais mais inclusivos da Europa, com menos de 0,4\% de alunos com NEE, estudando em escolas especiais.

Considerando que vários estudos internacionais demonstram que, de modo geral, os professores concordam com a inclusão escolar, suas atitudes e percepções são menos positivas quando eles têm que incluir alunos com necessidades educativas especiais em suas próprias salas de aula.

Para a pesquisa, foram selecionados aleatoriamente 336 professores do ensino comum(68 da educação infantil, 133 do ensino fundamental, e 135 professores do ensino médio) da província de Alicante. Os resultados indicaram a aceitação dos princípios de inclusão, embora os dados sobre as habilidades dos professores, tempo, recursos materiais e suportes pessoais de inclusão foram consideradas insuficientes.

Professores da educação infantil e ensino fundamental apresentaram uma percepção mais positiva da inclusão escolar,em comparação aos professores do ensino médio. $\mathrm{O}$ mesmo resultado foi encontrado, em relação aos professores com mais apoio pessoal e recursos materiais, em comparação com aqueles com menos apoios e recursos(CHINER; CARDONA,2013).

\section{Polônia}

No artigo de Szumski e Karwowski (2012) são descritas as condições para o sucesso escolar de alunos com deficiência intelectual leve do ensino fundamental polonês. Na Polônia, existem três formas de escolarização do aluno com deficiência intelectual leve: as escolas especiais que concentram $40 \%$ dessa população, escolas integrativas 
com $24 \%$ e escolas regulares com $34 \%$ do total. As escolas integrativas foram criadas há cerca de 20 anos atrás, sendo que as classes integrativas são salas com um número reduzido de alunos (16 a 20 no máximo) destinadas a alunos com e sem NEE. A quantidade de alunos com NEE varia de três a cinco e dois professores atuam nessas salas, sendo um deles formado em educação especial (SZUMSKI; KARWOWSKI, 2012).Os alunos com NEE também podem estudar em escolas regulares, sendo a quantidade máxima por sala de dois alunos nessas condições. A mesma base curricular é aplicada para os três tipos de escolas.

De acordo com Szumski e Karwowski (2012), a colocação do aluno em um desses tipos de escola passa por um processo com duas etapas. $\mathrm{Na}$ primeira, a criança é avaliada por uma equipe de especialistas em uma clínica infantil local, sendo que a solicitação de avaliação é sempre conduzida a pedido dos pais. "Uma vez diagnosticada, os especialistas recomendam a melhor forma de educação para cada aluno em particular.” (SZUMSKI; KARWOWSKI, 2012, p.1618, tradução nossa). No país, os pais podem apontar suas preferências, em uma reunião com a equipe; porém, essa opinião não é conclusiva. $\mathrm{Na}$ segunda etapa do processo, a criança é devidamente colocada na escola escolhida pela equipe, o que é garantido pelas autoridades educacionais locais.

Para esses autores, a meta do estudo foi examinar se o sucesso escolar de crianças com deficiência intelectual leve está associado ao nível socioeconômico da família e ao engajamento dos pais, uma vez que a literatura já aponta que a cooperação família-escola é essencial para o sucesso dos alunos e para a redução das tensões no processo de inclusão. Na pesquisa em questão participaram 605 alunos, com deficiência intelectual leve de escolas integrativas, regulares e especiais, e seus pais(SZUMSKI; KARWOWSKI, 2012). 
Os autores verificaram que o nível socioeconômico foi positivamente associado com colocação de crianças, em escolas integradoras e regulares, em vez de escolas especiais, bem como com maior envolvimento dos pais nos estudos dos seus filhos. Isso significa que quanto mais alto o nível socioeconômico dos pais, maior a probabilidade desses alunos com DI leve frequentarem escolas integrativas e regulares. Essas crianças frequentemente recebem o tipo de escolarização que os pais consideram como sendo melhor para elas, uma vez que esses geralmente valorizam mais formas de escolarização inclusivas. $\mathrm{O}$ sucesso escolar também foi fortemente associadoao engajamento dos pais, sendo os pais com nível socioeconômico mais alto mais engajados. Por outro lado, crianças com deficiência intelectual com pais com nível socioeconômico mais baixos são, na maioria das vezes, enviadas para as escolas especiais, mesmo quando seus pais almejam o contrário.

Uma análise crítica do texto de Szumski e Karwowski (2012) permite inferir que os pais têm pouca voz sobre a colocação dos filhos nas escolas da Polônia. Suas opiniões são consideradas; porém, a decisão final é tomada por uma equipe aparentemente médica, pois a avaliação é realizada em uma clínica. Isso é claro, tendo provavelmente como viés o nível socioeconômico e o engajamento da família.

\section{Países Nórdicos}

A realidade nórdica é tratada por Takala, et al (2012).O artigo descreve vários pontos de vista de alunos de educação especialsobre a inclusão e tem como objetivo analisar com mais profundidade os desafios da introdução da educação inclusiva com o professor de educação especial, assim como discutir as possíveis implicações Olh@res, Guarulhos, v. 3, n. 1, p. 168-193. Maio, 2015. 
destas descobertas sobre os professores de educação especial e regular (TAKALA, et al, 2012).Foram analisadas declarações feitas por estudantes na Finlândia, Noruega e Suécia.

Os autores discutem que a formação em educação especial na Escandinávia é diferente entre seus países. Hausstätter e Takala (2008 apud TAKALA, et al, 2012), por exemplo, apontam que a inclusão desempenha um papel central na formação do educador especial da Noruega e da Suécia, mais do que na Finlândia. Cada um desses países tem desenvolvido sua própria resposta às propostas da UNESCO, de acordo com suas respectivas percepções e expectativas da educação. Na Noruega, não existe uma formação e uma profissão específica de professor especial, sendo que os alunos podem estudar Pedagogia Especial e utilizar o título de Pedagogo Especial. Na Finlândia, existe o curso de Educação Especial e seus profissionais são chamados de Educadores Especiais. Na Suécia têm-se as duas formações: educação especial e pedagogia especial. Os formados em pedagogia especial atuam na educação regular, auxiliando os professores na adaptação do ensino e no sistema da escola para receber a criança com NEE (TAKALA, et al, 2012).

O artigo discute também um fato importante que acontece não apenas na realidade nórdica. Os autores sinalizam que a implantação da política de inclusão escolar depende de políticas que são implementadas pelos professores e escolas, independentemente de suas opiniões pessoais e, muitas vezes, sem recorrer a formação, recursos extras ou evidênciasde que essa prática seja efetiva. Consequentemente, os professores têm pouco senso de propriedade do conceito de inclusão (TAKALA, et al, 2012).

Por conta dessa imposição, os professores sentem que não foram treinados para lidar com os problemas em educar um estudante do público alvo da educação especial, mas reconhecem que precisam aprender mais sobre isso. Em muitos países e no caso de muitos Olh@res, Guarulhos, v. 3, n. 1, p. 168-193. Maio, 2015. 
professores é a dificuldade na compreensão do próprio princípio da inclusão escolar que dificultará sua prática com esses alunos. Para Florian e Rouse (2009 apud TAKALA, et al, 2012), uma maneira de lidar com esses desafios seria envolver, engajar os professores a explorarem os possíveis benefícios da inclusão.

Para a realização da pesquisa, foi utilizado um questionário com uma pergunta fechada e duas perguntas abertas em todos os países. Os dados foram coletados em um período de dois anos, com alunos dos cursos de educação especial dos três países. Os resultados mostraram que a grande maioria dos estudantes noruegueses apoia a inclusão, enquanto os estudantes finlandeses expressammaisreservas. Os argumentos sobre a inclusão dos estudantes noruegueses foram focados nos benefícios para alunos; dos finlandeses, focados no professor e suas dificuldades, ou seja, em aspectos negativos da inclusão. Os suecos apresentaram ambas as opiniões. De qualquer forma, os resultados parecem refletir a política educacional nesses países (TAKALA, et al, 2012).

\section{Itália}

O trabalho de revisão "Positive effects of the placement of students with intellectual developmental disabilities in typical class", de Vianello e Lanfranchi (2011) aponta os resultados da comparação de cinco diferentes trabalhos que analisaram os efeitos da inclusão de alunos com DI, em classes regulares, em relação ao desenvolvimento psicológico, acadêmico e adaptativo.Vianello e Lanfranchi (2011) atentam para o fato de que na Itália, diferentemente de muitos países, todos os alunos com deficiência intelectual e mais de $97 \%$ dos alunos com deficiência de modo geral, são educados em salas de aula típicas (comuns), juntamente com os seus colegas sem deficiência. 
A comparação dos cinco estudos permitiu a criação de categorias de comparação. Os resultados com a análise mostram que a classe típica promove um melhor desenvolvimento psicológico, principalmente do ponto de vista social, uma vez que a sua inclusão promove, por exemplo, a amizade e aceitação social, melhora no autoconceito, maior índice de comportamentos adequados e menos comportamentos de oposição. Os estudos comparados também demonstram que os alunos com deficiência intelectual apresentam resultados acadêmicos mais elevados, quando escolarizados em salas comuns.

Em visita ao Website da European Agency é possível consultar os dados de inclusão escolar,nos países europeus, no ano de 2013, produzidos pela European Agency for Development in Special Needs Education. Os dados foram obtidos a partir de fontes ministeriais dos países. Segue abaixo uma tabela elaborada a partir desses dados, de acordo com o material fornecido pela agência, em relação aos países mencionados nos artigos de revisão da presente pesquisa. Será utilizado o termo NEE (necessidades educacionais especiais), por ser conceito utilizado no documento (SEN-Special Educational Needs).

Tabela1 - Quantidade de alunos com Necessidades Educacionais Especiais em escolas especiais, salas especiais e salas comuns por país europeu (EUROPEAN AGENCY, 2012).

\begin{tabular}{|c|c|c|c|c|}
\hline País & Alunos com NEE em & Setor Público & Setor Privado & Total \\
\hline \multirow[t]{3}{*}{ Alemanha } & Escolas Especiais & 306,737 & 71,185 & 377,922 \\
\hline & Classes Especiais & -* & - & - \\
\hline & Ambientes totalmente inclusivos & - & - & 102,102 \\
\hline \multirow[t]{3}{*}{ Áustria } & Escolas Especiais & 9,736 & 459 & 10,195 \\
\hline & Classes Especiais & 2,039 & 98 & 2,137 \\
\hline & Ambientes totalmente inclusivos ${ }^{4}$ & 15,047 & 274 & 15,321 \\
\hline \multirow[t]{3}{*}{ Espanha } & Escolas Especiais & 8,356 & 6,554 & 14,910 \\
\hline & Classes Especiais & 1,563 & 1,226 & 2,789 \\
\hline & Ambientes totalmente inclusivos & 68,272 & 21,006 & 89,278 \\
\hline \multirow[t]{2}{*}{ Finlândia } & Escolas Especiais & 5,972 & 261 & 6,233 \\
\hline & Classes Especiais & 14,462 & 0 & 14,462 \\
\hline
\end{tabular}

\footnotetext{
${ }^{4}$ A tradução dada para o termo fully inclusive settings apresentado nos dados originais foi de ambientes totalmente inclusivos. A interpretação permite inferir que se trata de salas de aula comuns em escolas regulares.

Olh@res, Guarulhos, v. 3, n. 1, p. 168-193. Maio, 2015.
} 


\begin{tabular}{|c|c|c|c|c|}
\hline & Ambientes totalmente inclusivos & 24,744 & 0 & 24,744 \\
\hline \multirow[t]{3}{*}{ Holanda } & Escolas Especiais & 66,085 & $-*^{5}$ & 66,085 \\
\hline & Classes Especiais & - & - & - \\
\hline & Ambientes totalmente inclusivos & 40,613 & - & 40,613 \\
\hline \multirow[t]{3}{*}{ Itália } & Escolas Especiais & 1,835 & - & 1,835 \\
\hline & Classes Especiais & $0^{6}$ & 0 & 0 \\
\hline & Ambientes totalmente inclusivos & 177,174 & 10,554 & 187,728 \\
\hline \multirow[t]{3}{*}{ Irlanda } & Escolas Especiais & 5,410 & - & 5,410 \\
\hline & Classes Especiais & 2,302 & - & 2,302 \\
\hline & Ambientes totalmente inclusivos & 31,404 & - & 31,404 \\
\hline \multirow[t]{3}{*}{ Noruega } & Escolas Especiais & 1,821 & 60 & 1,881 \\
\hline & Classes Especiais & 3,103 & 98 & 3,201 \\
\hline & Ambientes totalmente inclusivos & 45,639 & 1,458 & 47,097 \\
\hline \multirow[t]{3}{*}{ Polônia } & Escolas Especiais & 86,587 & 4,496 & 91,083 \\
\hline & Classes Especiais & 2,501 & 87 & 2,588 \\
\hline & Ambientes totalmente inclusivos ${ }^{7}$ & 65,782 & 1,393 & 67,175 \\
\hline \multirow{3}{*}{$\begin{array}{l}\text { Reino } \\
\text { Unido }^{8}\end{array}$} & Escolas Especiais & 95,300 & 14,202 & 109,502 \\
\hline & Classes Especiais & 20,242 & - & 20,242 \\
\hline & Ambientes totalmente inclusivos & 201,388 & - & 201,388 \\
\hline \multirow[t]{3}{*}{ Suécia } & Escolas Especiais & 501 & 0 & 501 \\
\hline & Classes Especiais & 11,616 & 499 & 12,115 \\
\hline & Ambientes totalmente inclusivos & - & - & - \\
\hline
\end{tabular}

Fonte: European Agency for Development in Special Needs Education. Country Data, 2012.

Os dados demonstram que, em alguns dos países citados, o setor público é o responsável pela educação das crianças público alvo da educação especial, como é o caso da Finlândia, da Suécia e da Itália. É possível notar que, com exceção da Polônia, nos demais países, a maioria dos alunos com $\mathrm{NEE}^{9}$ já se encontram nos chamados ambientes totalmente inclusivo.

\section{Considerações Finais}

\footnotetext{
${ }^{5} \mathrm{O}$ traço indica que não há dados disponíveis.

${ }^{6}$ A legislação italiana em vigor não prevê a possibilidade da criação de classes especiais ou segregadas em escolas regulares. Os alunos são incluídos diretamente em salas comuns.

7 Lembra-se que no caso da Polônia, esse dado engloba crianças nas escolas integrativas e escolas regulares.

${ }^{8}$ Os dados da European Agency for Development in Special Needs Education referentes ao Reino Unido são disponibilizados individualmente para Inglaterra, Irlanda do Norte, Escócia e País de Gales. Portanto, os dados apresentados na Tabela 1 referem-se a somatória dos dados individuais de cada país.

${ }^{9}$ Atenta-se para o fato de que o termo SEN (traduzido como NEE) engloba diferentes definições para cada país.

Olh@res, Guarulhos, v. 3, n. 1, p. 168-193. Maio, 2015.
} 
A análise das pesquisas internacionais permitiu levantar vários tópicos importantes que merecem ser abordados em relação à escolarização de alunos com deficiência intelectual, tanto nos países europeus como na realidade brasileira.As pesquisas apontaram que, quando em escolas inclusivas, os alunos com deficiência intelectual apresentam melhores resultados acadêmicos. Várias pesquisas mostram que, quando em ambiente mais desafiador, o aluno com deficiência intelectual pode adquirir mais habilidades acadêmicas. Entretanto, alguns estudos sugerem que outras variáveis importantes possam estar em jogo, no caso desse aparente maior sucesso da escolarização em escolas comuns, tais como o nível socioeconômico da família, o envolvimento parental na escolarização dos filhos com deficiência intelectual, o grau e severidade da deficiência etc. Tais achados indicam a necessidade de mais estudos, que possam isolar essas variáveis.

Outro tópico relevantefoia importância da participação da família. De modo geral, as pesquisas internacionais apontam a importância da participação dos pais na escolha do tipo de escolarização dos filhos. Para isso, faz-se necessário que eles sejam empoderados, para decidir sobre questões que lhes dizem respeito e adquirirem controle sobre as suas vidas. $\mathrm{O}$ conceito de empoderamento remete a um conjunto de esforços, com vista à autonomia, para transferir ou devolver o controle da própria vida para a pessoa, ao invés de tutelá-la ou tentar controlála (MENDES, 2006).

Além de se perceberemcomo responsáveis, é necessário que os pais possam participar como iguais no processo de tomada de decisões sobre serviços a serem oferecidos para seus filhos e a si próprios. De acordo com Silva e Mendes (2008), para realizar o empoderamento dos pais, os profissionais devem"informá-los sobre seus direitos; 
ajudá-los a elaborar questões para o médico; orientá-los a expressarem suas opiniões e oferecer suporte moral aos pais" (p. 232, 233).

Culturalmente em nosso país, tem-se a percepção de que a responsabilidade pela educação e por suas implicações é apenas da escola. Para que ocorra uma mudança, é fundamental que os profissionais da escola estimulem a participação dos pais, para que esses sintam-se realmente responsáveis pela educação dos filhos.

Outra variável importante apontada nos estudos, quando se pensa em qual é a melhor forma de escolarização, é a gravidade da deficiência. As pesquisas demonstraram que quanto mais grave a deficiência é percebida, maiores as chances dos pais e educadores optarem pela escola especial. A necessidade de um plano de transição entre as duas formas de escolarização também é apontada como relevante para uma inclusão escolar bem sucedida.

E, finalmente, muitas pesquisas demonstraram que a inclusão só passa a fazer sentido quando o professor e a escola sentem-se como partes integrantes desse processo. Sem esse senso de responsabilidade pelo processo, a escola toma a postura de mera expectadora do processo de inclusão escolar. Finalmente cumpre destacar que os resultados, em termos de sucesso ou fracasso das políticas e práticas inclusivas apontados nesses estudos não podem ser analisados sem considerar os contextos próprios de cada país. Bons resultados, por exemplo, aparecem em países que investem, colocando à disposição da escola os apoios e recursos necessários, e um dos apoios mais comuns tem sido a presença de professores especializados na sala de aula, onde se encontram estudantes do público alvo da Educação Especial.Tais aspectos são imprescindíveis para viabilizar a qualidade de ensino do aluno com deficiência intelectual, independentemente do tipo de escolarização

escolhida 
Referências bibliográficas

BEYER, H. O. Inclusão e Avaliação na Escola de Alunos com Necessidades Educacionais Especiais. Porto Alegre. Editora Mediação, 2010.2ed.

BODE, H.; HIRNER, V. Kinder mit Lernstörungen und Behinderungen in integrativen Schulen oder in Sonderschulen? Die Sichtweise von Eltern und Fachleuten. Klin Padiatr, New York, v.225, n.2, p. 57-63, 2013.

BOER, A., et al.Which variables relate to the attitudes of teachers, parents and peers towards students with special educational needs in regular education? Educational Studies, v.38, n.4, p.433-448, 2012.

BUCKLEY S, ET. AL.A comparison of mainstream and special education for teenagers with Down syndrome: implications for parents and teachers. Down Syndrome Research and Practice,v.9, n3, p.54-67, 2006.

BRASIL.Decreto 7611, de 17 de novembro de 2011. Dispõe sobre o atendimento educacional especializado, Brasília, 2011.

CHINER, E.; CARDONA, M. C. Inclusive Education in Spain: how do skills, resources, and supports affect regular education teachers' perceptions of inclusion? International Journal of Inclusive Education, v.17, n.5, 2013.

EUROPEAN AGENCY FOR DEVELOPMENT IN SPECIAL NEEDS EDUCATION. Disponível em: < https://www.european-agency.org/>. Acesso em 10 out. 2014.

FLORIAN, L.; ROUSE, m.. The inclusive practice project in Scotland. Teacher Education for Inclusive Education, v.25, p.594-601, 2009.

GASTEIGER-KLICPERA, B., et al. Attitudes and experiences of parents regarding inclusive and special school education for children with learning and intellectual disabilities. International Journal of Inclusive Education, v.17, n.7, p.663-681, 2013.

GIL, A. C. Como elaborar projetos de pesquisa. 3. ed. São Paulo: Atlas, 1991.

GRAAF, G.; HOVE, G. V.; HAVEMAN, M. More academics in regular schools? The effect of regular versus special school placement on academic skills in Dutch primary school students with Down syndrome. Journal of Intellectual Disability Research, v.57, n.1, p.21-38, 2013.

HAUSSTÄTTER, R.C.; TAKALA, M. The core of special teacher education: A comparison of Finland and in Norway. European Journal of Special Education, v.23, n. 2, p. 121-34, 2008.

KELLY, A. et al. Challenges in Implementing Inclusive Education in Ireland: Principal's Views of the Reasons Students Aged 12+ Are Seeking Enrollment to Special Schools. Journal of Policy and Practice in Intellectual Disabilities, v.11, n.1, p. 6881 , 
MACARTNEY, B.; MORTON, M. Kinds of participation: teacher and special education perceptions and practices of 'inclusion' in early childhood and primary school settings. International Journal of Inclusive Education, v. 17, n.8, Edição Especial, 2013.

MENDES, E. G. A radicalizacao do debate sobre inclusão escolar no Brasil. Revista Brasileira de Educação, v. 11, n. 33, p. 387-405, 2006.

Breve histórico da educação especial no Brasil. In: Revista Educación y Pedagogía, v. 22, n. 57, mayo-agosto, 2010.

PADILHA, A. M. O que fazer para não excluir Davi, Hilda, Diogo.... Em: GÓES, M. C. R. e LAPLANE, A. L. F. Políticas e Práticas de Educação Inclusiva. Campinas/SP, Autores Associados, 2004.

SILVA, A. M.; MENDES, E. G. Família de crianças com deficiência e profissionais: componentes da parceria colaborativa na escola. Rev. bras. educ. espec., Marília, v. 14, n. 2, p.217-234, 2008 .

SOUTHHOLLAND ANGLOINFO.Special Needs Education in the Netherlands.Disponível em $:<$ http://southholland.angloinfo.com/information/family/schooling-education/specialneeds-education/>. Acesso em 10 Abr. 2014.

SZUMSKI, G.; KARWOWSKI, M. School achievement of children with intellectual disability: The role of socioeconomic status, placement, and parents' engagement.Research in Developmental Disabilities, v.33, p.1615-1625, 2012.

TAKALA, M. et al. Inclusion seen by student teachers in special education: differences among Finnish, Norwegian and Swedish students.European Journal of Teacher Education, v.33, n.5, p.1-21, 2012.

VELTRONE, A. A. Inclusão escolar do aluno com deficiência intelectual no estado de São Paulo: identificação e caracterização. Tese (Doutorado) - Programa de Pós Graduação em Educação Especial, Centro de Educação e Ciência Humanas, Universidade Federal de São Carlos, São Carlos, 2011.

RENZO VIANELLO, R. ; LANFRANCHI, S. Positive effects of the placement of students with intellectual developmental disabilities in typical class. Life Span and Disability. v.1, p.75-84, 2011.

WEB OF SCIENCE. WEB OF SCIENTE - IP \& SCIENCE. Thomson Reuters. Disponível em: <http://isiknowledge.com/>. Acesso em 15 mar. 2014.

Recebido para publicação em 02 de fevereiro de 2015

Aprovado em 06 de abril de 2015

Olh@res, Guarulhos, v. 3, n. 1, p. 168-193. Maio, 2015. 